ARTICLE

\title{
Peer Effect of Middle School Students: A Natural Experiment Based on Puberty Developmental Maturity
}

\author{
Yuhong Du, Yanbin Guo \\ Beijing Normal University, Beijing 100875, China
}

\begin{abstract}
Peer is an important factor affecting the academic performance of middle school students. Domestic research has discussed this issue, but there are still some shortcomings in solving endogeneity aspects. Therefore, this study used the random effect of natural changes in pubertal development and maturity of middle school students in two years adjacent to the same class to identify peer effects due to changes in pubertal development and maturity; at the same time, first-order difference and quantile regression are used to solve the endogeneity problems in general regression analysis. We found that girls' developmental maturity is significantly negatively related to their performance, and boys' developmental maturity is significantly positively related to their performance, which indicates that there is a gender difference in the impact of adolescent developmental maturity on academic performance of middle school students. In addition, the peer effect is also heterogeneous, that is, in overall, the lower the development maturity of girls in a class, the more conducive to the improvement of student performance; the higher the maturity of students in class, the more conducive to the improvement of student performance. The findings of this study have certain policy implications for adjusting the school age of school-age children.
\end{abstract}

Best Evid Chin Edu 2019; 4(1):425-442.

Doi: 10.15354/bece.20.ar019.

Keywords: Peer Effect; Natural Experiment; Developmental Maturity; Heterogeneity

Correspondence to: Yuhong Du, Professor, Director, Faculty of Education, Beijing Normal University, Beijing 100875, China.E-mail: dyh@bnu.edu.cn. 


\section{Introduction}

T $\mathrm{N}$ the framework of the educational production function, family, school, student personal characteristics and peers are all important factors affecting student academic performance. In the past few decades, a large number of studies have conducted a lot of fruitful discussions on the factors of families, schools, and students, and can accurately estimate the role of each factor; however, there is no clear conclusion about the role of peers, especially in the mainland of China, and is particularly very rare on the peer effects in middle school students. Therefore, this study attempts to analyze the peer effect of middle school students in mainland of China.

\section{Literature Review}

Peer effect is also called peer effect. Research on the role of peers in education can be traced back to the Coleman report (1966). The study found that peers, families, teachers, schools and other factors affect students' academic performance. Most of the early studies were limited to the discussion of the relationship between peers and academic performance (Caldas \& Bankston, 1997; Link \& Mulligan, 1991), and did not overcome the endogeneity problem in estimation. In 2000, Hoxby (2000b) for the first time analyzed the peer effect in schools by using the random factors of the birth of the population, and relatively accurately estimated the peer effect in education. Hoxby's idea of using natural experiments to overcome endogeneity to estimate peer effects has gradually gained importance in subsequent related research.

\section{Concepts, Pathways, and Heterogeneity}

The definition of peer is the first step in the study of peer effects, and it is also a major challenge in the study of peer effects. Early studies often chose classmates (Sacerdote, 2001; Zimmerman, 2003), class level (Ding \& Lehrer, 2007), and grade level (Hoxby, 2000b; Hanushek, et al., 2003) as individual student peers. In recent years, there have been an increasing number of researches using students' self-reported friends (Ilmarinen, et al., 2017; Lavy \& Sand, 2018) as peers for analysis. This social networkbased peer effect is obviously more real, but data acquisition is difficult and generally difficult to achieve.

\footnotetext{
About the author: Yanbin Guo, Graduate Candidate, Beijing Normal University, Beijing 100875, China. E-mail: ybguo@mail.bnu.edu.cn

Funding: This study was supported by the 2015 major research project of the Ministry of Education's Philosophy and Social Science research project "Relationship and Contribution of Education and Economic Development" (Project \#: 15JZD040).

Conflict of Interests: None.
} 
In addition to defining peers, clarifying the concept of peer effects is also the basis for conducting related research. There has been no consensus on the concept of peer effects. At present, there are several representative views: Sacerdote (2011) believed that the peer effect includes almost all external factors that are not market- or price-driven, such as peer background, current behavior, or educational attainment. Lu \& Zhang (2007) believed that the peer effect is the interaction between people, which directly affects the performance of relevant actors. Du \& Yuan (2016) defined the peer effect in education as the influence of the background, behavior, and performance of peers in dormitories, classes, grades, or schools on student performance or behavior. There are various ways to influence this effect. Based on the above analysis, the author considers the effects of natural characteristics, background, behavior, performance, and non-cognitive characteristics of peers in schools on student performance, behavior, and non-cognitive skills as peer effects.

There are many ways in which the peer effect can play a role, and peer performance is not the only way to generate peer effects. Hoxby (2000b) believed that the ways of peer effect include: mutual help between students; students' inherent ability to affect peers through the spillover effect of knowledge and the impact on class positioning; behaviors affected by the environment also affect peers; disability, race, gender, and family income also play a role; peer effects can also take a part through the attitudes of teachers and administrators to students.

Earlier studies on peer effects were mostly limited to the description of correlations. Strategies such as ordinary least squares were often used, but these methods did not solve the problem of endogeneity well. One of the challenges in estimating peer effects is endogeneity. According to the theories of Manski (1993), Manski (1995), and Moffitt (2000), the endogeneity of the peer effect estimation mainly comes from Selection Bias and Reflection Problem. Parents often choose a school, class, or even a teacher for their children based on their family economic and social background, making it difficult to simply attribute changes in students' academic performance to peers, which is the so-called self-selection bias. Individual students and their peers live in the same environment and receive the same education, and there will inevitably be mutual influences between each other. That is, students are not only affected by peers, but also students themselves. Moreover, these two effects often occur at the same time, and it is often difficult to separate them, which causes the problem of simultaneous bias in the estimation of peer effects.

Peer effects are also heterogeneous, meaning that students of different types or abilities may be affected to different degrees and directions by peers. Hoxby (2000b) found that the peer effect is asymmetric. Subsequent research has gradually verified this conclusion, but the existing researches on the direction of heterogeneity were not completely consistent. The conclusions mainly include two major categories: the smaller the differences in student abilities or types, the better the student's development (Ding \& Lehrer, 2007; Hoxby \& Weingarth, 2005), and the larger the differences in student abilities or types, the better the student's development (Carman \& Zhang, 2012; Vigdor \& Nechyba, 2006). In addition, the identification of heterogeneity often uses two strate- 
gies: interaction (Hoxby \& Weingarth, 2005) or quantile regression (Ding \& Lehrer, 2007; Hanushek, et al., 2003).

\section{Recognition Strategy}

In recent years, with the continuous improvement of causal inference technology, the identification of peer effects has become more accurate. Natural experiments (Angrist \& Lang, 2004; Hoxby, 2000b) and quasi-experimental studies have gradually attracted attention. The key to natural experiments is to find the appropriate random factors. Since Hoxby (2000b), the research of natural experiments has been favored by the social sciences. When it comes to natural experiments, you first need to clarify the relationship among Random Control Experiment, Natural Experiment, and Conventional Observational Studies.

Standard random experiments generally need to meet three conditions (Freedman et al, 2007). First, compare. Compare the differences between the experimental group and the control group after the experiment. Second, random assignment. The subjects were randomly assigned to the control group and the experimental group. Third, manipulation or intervention by researcher. The researchers gave different experimental treatments to the experimental group and the control group. The ideal random experiment needs to fully meet the three conditions mentioned above. Traditional observational research can often only meet the first condition, that is, "comparing" the differences between different research objects, and the conditions of "random allocation" and "human intervention / control" are often difficult to meet. Natural experiment is a research method between random experiment and traditional observational research.

Natural experiments are different from traditional observational studies. Because the former can meet the first condition of random experiments, that is, "comparison", it can at least guarantee that the sample is random (Random) or approximately random (As Random), which is also a natural experiment closer to random experiments than traditional observational research. The reason is that it should be said that randomness is the key to natural experiments (Dunning, 2012). Therefore, finding enough exogenous and uncontrolled factors is a prerequisite for conducting natural experiments. "Nature" in natural experiments often comes from some phenomena in social life: for example: (1) exogenous shocks: disasters, climate, economic fluctuations; (2) individual biological factors: birth, aging, disease, death, etc. (3) geographical location: topography, borders; (4) man-made purely random events: draw lots, test scores, government policies, etc. In addition, natural experiments are also observational studies, because natural experiments also cannot satisfy the condition of "control" in random experiments, and the experimental process cannot be controlled by researchers. Natural experiment, as a causal inference strategy closest to random experiment, provides us with a reliable identification strategy, which overcomes the disadvantages of traditional observational research to a certain extent.

However, we must also admit that it is often difficult to provide the conditions for causal analysis of everything we want to evaluate in social life. The analysis of specific groups based on natural experiments can often only be regarded as a local average 
treatment effect (LATE) (Dunning, 2012). The evaluation of natural experiments is generally carried out from three aspects, Plausibility, Credibility, and Relevance (Dunning, 2012). Plausibility refers to the use of quantitative and qualitative methods to demonstrate that the allocation process of natural experiments is random; Credibility emphasizes that the causal relationship of the model is convincing, that is, the disposal variable is independent of other factors that affect the outcome variable; Relevance refers to the problem and intervention to be studied Whether it is substantially related to the external validity of the experimental results. The excellent properties of natural experiments in solving endogeneity make it an important choice for identifying peer effects. Hoxby (2000b) used the random factors of birth changes to identify the effect peer brought by gender and race. The key of this research is to cleverly find the natural changes in student gender and changes in student performance caused by natural changes in race. It overcomes the corresponding endogenous problem, thus setting a precedent for identifying the peer effect by natural experiments.

\section{Effective Natural Factors}

As a multi-disciplinary issue, the study of peer effects has been involved to varying degrees in economics, psychology (Ilmarinen, et al., 2017), and sociology (Cheng, 2017). In recent years, influenced by multidisciplinary, interdisciplinary, and transdisciplinary trends, different disciplines have learned from each other in terms of research content and research methods. Affected by psychology and sociology, a lot of researches have been done on the relationship between adolescent developmental maturity and students' academic performance. The maturity of puberty is a natural phenomenon of life, and it is a normal physiological phenomenon that does not transfer by human will. Puberty refers to the physical development of people who were originally able to have children (McKechnie, 1979). Physiological research often uses the two indicators of Pubertal Status and Pubertal Timing to describe the physical development of adolescence. The former refers to changes in the body of an individual, including secondary sexual characteristics, and the latter refers to the sooner or later of these changes compared to their peers. To characterize the differences in pubertal development in different individuals, the term "pubertal mature pubertal development" was introduced, and it is often measured as soon as puberty enters.

Adolescent developmental maturity has a certain effect on individual cognitive skills and non-cognitive skills, and this effect is direct, that is, developmental maturity often depends on the sooner or later of puberty. A study by Beltz and Berenbaum (2013) found that the effects of adolescents entering puberty on their cognitive development and brain development differ by gender. They used the characteristics of male first spermatorrhea and female menarche as the proxy variables for puberty. The study found that boys who entered early adolescence performed better on cognitive tests than boys who entered later adolescence; for women, this effect was not significant. Cavanagh and Riegle-Crumb (2007) also used girls' self-reported menarche as a proxy variable for early and late puberty. They found that girls who matured earlier had lower GPA in high school, were more likely to encounter failure in high school courses, and graduated 
from high school is less likely. Research by Daniel et al. (1982) found that maturity at puberty affects both cognitive and non-cognitive performance of students. Compared with boys with normal developmental maturity, boys who have late maturity (secondary sexual development score below $80 \%$ of participants) have worse cognitive scores and lower expectations from their parents; they have earlier maturity of boys performed better on cognitive scores than boys of moderate maturity and later maturity. Kristian and Tuomas (2017) used the development of adolescent secondary sexual characteristics as a proxy variable for early and late puberty. The study found that students who matured later (including boys and girls) have lower cognitive scores, worse academic performance, and Future income will be lower. This study believes that there is a difference between men and women entering puberty, but this is not the reason for the differences between men and women in cognitive ability and academic performance (Koerselman \& Pekkarinen, 2017).

In summary, adolescent developmental maturity is a natural factor that has a direct impact on students' academic performance, parental expectations, etc., and most studies support the conclusion that boys mature earlier and girls mature later are more favorable for student development. In this sense, the influence of peer development maturity on student achievement can be regarded as a peer effect. Based on this, this study attempts to supplement and develop the existing research from the following three aspects: First, we have overcome the problems of self-selection bias and synchrony bias commonly encountered in the estimation of peer effects. This study uses natural experiments on changes in adolescent developmental maturity to more accurately estimate the peer effect brought by adolescent developmental maturity. Second, it enriches the related theories of peer effects. This research combines the research results of psychology and physiology, and focuses on the influence of the physiological characteristics of peers on students' academic performance, which enriches the research content of peer effects to a certain extent. Of course, puberty developmental maturity is just one type of peer effect, and the overall analysis of all types of peer effect has yet to be explored. Third, the external validity of the study is higher. In the past, researches on peer effects mostly focused on a certain school, region, or project. The research on peer effects at the national level is still relatively limited. This study uses the tracking data of middle school students in mainland China to analyze this problem to a certain extent. This improves the applicability of the conclusion.

The following structural arrangement of this article is as follows: The third part introduces the model and data sources; the fourth part gives descriptive statistical results, the results of econometric analysis, and the robustness test; the fifth part gives research enlightenment and shortcomings.

\section{Research Design}

\section{Empirical Strategy}

\section{Natural Experiment}


The recognition of peer effects is inseparable from the clever application of causal inference technology. Therefore, finding suitable random factors is very important for the construction of the entire model. This factor must not only affect the academic performance of peers, but also ensure that it is not affected by human factors. We use the maturity of middle school students as a random factor to identify peer effects. In the process of choosing a school and class, parents rarely consider the maturity of their classmates, and developmental maturity often has a significant impact on their academic performance. In addition, from the perspective of the educational production function, the factors affecting the average grade of the class include factors such as family characteristics, school characteristics, and personal characteristics, but many factors will not change significantly in the short term. For example: the overall ability of class students, the family economic background of the class students as a whole, the school environment, the characteristics of teachers, etc., and other unobservable factors in the shortterm changes are random. Therefore, this article uses the number of students who entered puberty (that is, the first male nocturnal emission or female menarche) in the same class as the proxy variable for student development and maturity, and then eliminates other factors that affect the average grade of the class through a first order difference. The effect of changes in the developmental maturity of middle school students on the change in the average grade of a class during the year can be regarded as a peer effect. This design for identifying peer effects can be regarded as a natural experiment. The basic model established in this article is as follows:

$$
\begin{gathered}
\mathrm{A}_{\mathrm{cjg}}=\alpha_{0 \mathrm{~g}}+\alpha_{1} \mathrm{P}_{\mathrm{cjg}}^{\mathrm{mat}}+\alpha_{2} \mathrm{~S}_{\mathrm{cjg}}+\alpha_{3} \mathrm{I}_{\mathrm{cig}}+\alpha_{4} \mathrm{~F}_{\mathrm{cjg}}+\varepsilon_{\mathrm{cjg}} \\
\mathrm{A}_{\mathrm{cjg}-1}=\alpha_{0 \mathrm{~g}-1}+\alpha_{1} \mathrm{P}_{\mathrm{cjg}-1}^{\mathrm{mat}}+\alpha_{2} \mathrm{~S}_{\mathrm{cjg}-1}+\alpha_{3} \mathrm{I}_{\mathrm{cig}-1}+\alpha_{4} \mathrm{~F}_{\mathrm{cjg}-1}+\varepsilon_{\mathrm{cjg}-1}
\end{gathered}
$$

$\mathrm{A}_{\text {cjg }}$ represents the average score of the academic performance (cognitive ability test) of grade $\mathrm{c}$ in class $\mathrm{g}$ of school $\mathrm{j}, \mathrm{P}_{\mathrm{cjg}}^{\mathrm{mat}}$ represents the maturity of the students in the class, and the corresponding coefficient $\alpha 1$ is the size of the companion effect concerned in this article; $S_{c j g}$ represents the share of students in the same class School characteristics; $\mathrm{I}_{\text {cig }}$ represents the average true ability of students in the same class; $\varepsilon_{\text {cjg }}$ is an unobservable error term.

We can obtain the following equation by first difference.

$$
\Delta \mathrm{A}_{\mathrm{cjg}}=\alpha_{0}+\alpha_{1} \Delta \mathrm{P}_{\mathrm{cjg}}^{\mathrm{mat}}+\Delta \varepsilon_{\mathrm{cjg}}
$$

Where the unobservable factor $\varepsilon_{\text {cjg }}$ is random, then $\Delta \mathrm{A}_{\text {cjg }}$ in Equation (3) has a normal distribution with a mean value of 0 . Equation (3) gives the relationship model between the development maturity of the students in the class and the average performance of all students in the class. $\Delta \mathrm{A}_{\text {cjg }}$ includes the results of students who have entered adolescence. Therefore, in order to further overcome the problem of possible simultaneous errors, we replace the student's grade $\Delta \mathrm{A}_{\mathrm{cjg}}$ in formulas (1) and (2) with the 
average grade $\Delta \mathrm{A}_{\text {cjg }}^{\prime}$ of students who have not yet entered adolescence in the same class, that is, $\Delta \mathrm{A}_{\text {cjg }}^{\prime}$ means that those in class c of class $g$ of school $\mathrm{j}$ have not entered adolescence. The average score of the students' academic performance, so through the difference, we can get a model similar to (3):

$$
\Delta \mathrm{A}_{\mathrm{cjg}}^{\prime}=\varphi_{0}+\delta_{1} \Delta \mathrm{P}_{\mathrm{cjg}}^{\mathrm{mat}}+\Delta \mu_{\mathrm{cjg}}
$$

and the corresponding coefficient $\delta 1$ is the size of the peer effect concerned in this article.

\section{Heterogeneity Model}

Studies (Ding \& Lehrer, 2007; Hoxby \& Weingarth, 2005) show that the peer effect is heterogeneous, that is, the direction and magnitude of peer influence on students at different levels may be different. We use the strategy of conditional quantile regression (Koenker \& Bassett, 1978) proposed by Koenker and Bassett to identify the heterogeneity of peer effects. Combined with the research object of this article, we set the quantile regression model as follows:

$$
\mathrm{Q}_{\theta}\left(\Delta \mathrm{A}_{\mathrm{cjg}}^{\prime} \mid \Delta \mathrm{P}_{\mathrm{cjg}}^{\mathrm{mat}}\right)=\alpha_{0}+\alpha_{1} \Delta \mathrm{P}_{\mathrm{cjg}}^{\mathrm{mat}}+\Delta \varepsilon_{\mathrm{cjg}}
$$

$\Delta \mathrm{A}_{\text {cjg }}^{\prime}$ represents the value of $\theta$ quantile given $\Delta \mathrm{P}_{\text {cjg }}^{\text {mat }}$. Quantile regression can estimate any percent and minimize the MSE function to obtain the estimator, which is equation (6).

$$
\begin{gathered}
\alpha_{1}^{\theta}= \\
\operatorname{argmin}\left\{\sum_{\Delta \mathrm{A}_{\mathrm{cjg}}^{\prime} \geq \varphi_{0}+\delta_{1} \Delta \mathrm{P}_{\mathrm{cjg}}^{\operatorname{mat}} \theta} \theta\left|\Delta \mathrm{A}_{\mathrm{cjg}}^{\prime}-\left(\varphi_{0}+\delta_{1} \Delta \mathrm{P}_{\mathrm{cjg}}^{\mathrm{mat}}\right)\right|+\sum_{\Delta \mathrm{A}_{\mathrm{cjg}}^{\prime}<\varphi_{0}+\delta_{1} \Delta \mathrm{P}_{\mathrm{cjg}}^{\operatorname{mat}}}(1-\right. \\
\theta \Delta \mathrm{Acjg}^{\prime}-\varphi 0+\delta 1 \Delta \mathrm{Pcjgmat}
\end{gathered}
$$

\section{Data Sources}

The data used in this article are micro-data from China Education Panel Survey (CEPS). CEPS uses PPS sampling to design a sampling frame based on the "six population" in four stages, covering 28 county-level units (counties, districts, and cities) randomly selected across the country with the average education level and population ratio as stratified variables. The sample is a good representation of mainland China. During the sampling process, 1-2 classes were sampled in each grade of each school, and all students in the selected classes were sampled. The survey took the 2013-2014 school year as a baseline and surveyed 10,279 seventh-grade students. In the 2014-2015 school year follow-up survey, a total of 9,449 seventh-grade students were successfully followed up with a follow-up rate of $91.9 \%$, and this is the representative of the situation in the 
country. The survey also surveyed the backgrounds of student parents, classroom teachers, class teachers, and school leaders. The relevant data can well meet the research needs of this article.

Each round of the CEPS survey will test the students' cognitive ability. The content of this test question does not involve the specific memorizing knowledge taught in the school curriculum, but measures the students' logical thinking and problem solving ability. Finally, the three-parameter project reflection theory (IRT) is used to convert the standard points into international standards and characteristics of national standardization. This study focuses on peer-level peer effects in schools and requires peer composition to remain stable for a certain period of time. As a result, we only kept data on 7,826 students from 184 classes in 96 schools that did not reclassify or merge during the two surveys. At the same time, 213 students who did not meet the study de$\operatorname{sign}^{\underline{1}}$ were deleted, and the remaining valid sample was $7,613^{\underline{2}}$ students in 184 classes of 96 schools.

\section{Results}

\section{Describe Statistical Results}

In combination with the literature review, this article summarizes the main factors that may affect the average grade of the class. Table 1 gives descriptive statistics of the main variables. From Table 1, we can find that from the core variables, the scores of the 8th grade students' academic performance have decreased compared with the 7th grade; in the same class, the students' average maturity, girls' and boys' maturity during the year increased by approximately $50.12 \%, 39.69 \%$, and $75.54 \%,{ }^{-}$respectively. It can be seen that a higher proportion of boys have entered adolescence within two years.

From the perspective of family characteristics, compared with the seventh grade, the average maximum years of schooling of parents and the proportion of only children have declined, with 0.3 years and $1 \%$ respectively. The decline in parents 'years of education may be caused by measurement errors, that is, the parents' education level was answered by the children in the first round of surveys, while the parents or their children's guardians answered in the second round of surveys. The decline in the proportion of only children may be related to the "The only child of one parent can have a second child" policy that was implemented nationwide in November 2013 and can be regarded as a random change.

The proportion of students with higher family socioeconomic status in the class increased by $1.5 \%$, this is majorly related to the type of community in which the student lives to identify the family socioeconomic status of the participated student. It is possible for the student residence community to change within two years, but this change is random, and it is difficult to have a substantial impact on student development and maturity in the short term. In terms of school characteristics, the nature of the school has not changed in two years; the school ranking has declined slightly. Affected by factors such as measurement error, the above changes are all within acceptable ranges. Descriptive statistical results generally support the hypothesis of this study. 


\section{Table 1. Summary Statistics of Main Characteristics.}

\begin{tabular}{|c|c|c|c|c|c|c|}
\hline Description of Variables & Type & Mean & SD & Min & $\operatorname{Max}$ & $\mathbf{N}$ \\
\hline \multicolumn{7}{|l|}{ Core Variables } \\
\hline $\begin{array}{l}\text { Class average score from stu- } \\
\text { dents not entering the puberty in } \\
\text { seventh grade }{ }^{[1]}\end{array}$ & Continuous & -0.171 & 0.581 & -1.707 & 1.466 & 2,589 \\
\hline $\begin{array}{l}\text { Class average score from stu- } \\
\text { dents not entering the puberty in } \\
\text { eighth grade }\end{array}$ & Continuous & -0.237 & 0.610 & -2.021 & 1.267 & 2,589 \\
\hline $\begin{array}{l}\text { Puberty maturity from all students } \\
\text { in seventh grade } e^{2 l}\end{array}$ & Continuous & 17.447 & 7.347 & 3 & 45 & 2,589 \\
\hline $\begin{array}{l}\text { Puberty maturity from all students } \\
\text { in eighth grade }\end{array}$ & Continuous & 26.191 & 8.234 & 6 & 55 & 2,589 \\
\hline $\begin{array}{l}\text { Puberty maturity from female } \\
\text { students in seventh grade }\end{array}$ & Continuous & 13.092 & 5.512 & 2 & 27 & 2,589 \\
\hline $\begin{array}{l}\text { Puberty maturity from female } \\
\text { students in eighth grade }\end{array}$ & Continuous & 18.288 & 5.873 & 3 & 33 & 2,589 \\
\hline $\begin{array}{l}\text { Puberty maturity from male stu- } \\
\text { dents in seventh grade }\end{array}$ & Continuous & 4.502 & 3.631 & 0 & 24 & 2,589 \\
\hline $\begin{array}{l}\text { Puberty maturity from male stu- } \\
\text { dents in eighth grade }\end{array}$ & Continuous & 7.903 & 4.677 & 0 & 28 & 2,589 \\
\hline \multicolumn{7}{|l|}{ Family Characteristics } \\
\hline $\begin{array}{l}\text { The ratio of classroom high SES } \\
\text { in seventh grade }\end{array}$ & Continuous & 0.385 & 0.292 & 0 & 1 & 2,589 \\
\hline $\begin{array}{l}\text { The ratio of classroom high SES } \\
\text { in eighth grade }\end{array}$ & Continuous & 0.400 & 0.288 & 0 & 1 & 2,589 \\
\hline $\begin{array}{l}\text { Class average education highest } \\
\text { years of parents in seventh } \\
\text { grade }\end{array}$ & Continuous & 16.47 & 1.104 & 12.90 & 19 & 2,589 \\
\hline $\begin{array}{l}\text { Class average education highest } \\
\text { years of parents in eighth }\end{array}$ & Continuous & 16.17 & 1.196 & 12.37 & 18.71 & 2,589 \\
\hline $\begin{array}{l}\text { The ratio of classroom single- } \\
\text { child in seventh grade }\end{array}$ & Continuous & 0.410 & 0.256 & 0 & 0.969 & 2,589 \\
\hline $\begin{array}{l}\text { The ratio of classroom single- } \\
\text { child in eighth grade }\end{array}$ & Continuous & 0.400 & 0.265 & 0 & 0.969 & 2,589 \\
\hline \multicolumn{7}{|l|}{ School Characteristics } \\
\hline $\begin{array}{l}\text { The property of school in seventh } \\
\text { grade }^{[4]}\end{array}$ & Discrete & 1.095 & 0.408 & 1 & 4 & 2,589 \\
\hline $\begin{array}{l}\text { The property of school in eighth } \\
\text { grade }\end{array}$ & Discrete & 1.095 & 0.408 & 1 & 4 & 2,589 \\
\hline $\begin{array}{l}\text { The rank of school in seventh } \\
\text { grade }\end{array}$ & Discrete & 4.123 & 0.680 & 2 & 5 & 2,560 \\
\hline $\begin{array}{l}\text { The rank of school in eighth } \\
\text { grade }\end{array}$ & Discrete & 4.174 & 0.755 & 1 & 5 & $2,589^{[5]}$ \\
\hline
\end{tabular}

Note:

[1]. The cognitive tests score range of two wave survey is -2.029 2.710,-3.137 2.063 respectively, and CEPS using z-scores.

[2]. Using the number of students entering the puberty (namely appearing the first spermatorrhea and menarche) as proxies of puberty maturity.

[3]. Illiteracy, primary schools, junior secondary schools, secondary vocational schools, vocational high schools, regular senior secondary schools, higher vocational colleges, undergraduate schools and graduate schools and above denoted 0 year, 6 years, 9 years, 12 years, 12 years, 12 years, 12 years, 16 years, 19 years, respectively

[4]. The property of school includes public school, private school subsidized by the government, ordinary private school and private school for children of migrant workers, which is denoted by 1, 2, 3 and 4, respectively.

[5]. There is a school that didn't complete the rank of school in eighth grade, so the sample size of the rank of school in seventh is 2589 . 


\section{Table 2. Puberty Maturity on Score for All Students.}

\begin{tabular}{llll}
\hline & Puberty & $\mathbf{R}^{2}$ & $\mathbf{N}$ \\
\hline Scores & $0.0386^{\star \star}(0.0193)$ & 0.2932 & 7,114 \\
\hline
\end{tabular}

Note: 1. The table controls for class average education highest years of parents, the ratio of only-child from the same classroom and the ratio of classroom single-child and includes school fixed effects. The number of sample size is the number of students.

2. Clustered standard errors are reported in parentheses and standard errors are clustered by class. 3. ${ }^{* *}: p<0.05$.

\section{Table 3. Peer Effects from Puberty Maturity.}

\begin{tabular}{lll}
\hline & $\begin{array}{l}\text { Puberty Maturity from } \\
\text { All Students }\end{array}$ & $\begin{array}{l}\text { Class Average Score from Students } \\
\text { Not Entering the Puberty }\end{array}$ \\
\hline $\begin{array}{l}\text { Puberty Maturity from } \\
\text { All Students }\end{array}$ & $0.0057^{* * *}(0.0011)$ & $0.0009(0.0020)$ \\
\hline $\mathrm{N}$ & 184 & 56 \\
\hline $\mathrm{R}^{2}$ & 0.0044 & 0.0001 \\
\hline
\end{tabular}

Note: 1. Robust standard errors is reported in parentheses

2. Each column represents a separate regression and the number of sample size is the number of class. 3. ${ }^{* * *}: p<0.01$.

\section{Table 4. Peer Effects from Puberty Maturity by Sex.}

\begin{tabular}{|c|c|c|c|c|}
\hline & \multicolumn{2}{|c|}{$\begin{array}{l}\text { Puberty Maturity from All Stu- } \\
\text { dents }\end{array}$} & \multicolumn{2}{|c|}{$\begin{array}{l}\text { Class Average Score from Stu- } \\
\text { dents not Entering the Puberty }\end{array}$} \\
\hline $\begin{array}{l}\text { Puberty Maturity } \\
\text { from Female Stu- } \\
\text { dents }\end{array}$ & $\begin{array}{l}-0.0106^{* *} \\
(0.0014)\end{array}$ & & $\begin{array}{l}-0.0142^{\star \star} \\
(0.0026)\end{array}$ & \\
\hline $\begin{array}{l}\text { Puberty Maturity } \\
\text { from Male Stu- } \\
\text { dents }\end{array}$ & & $0.0376^{\star \star *}(0.0018$ & & $0.0338^{* * *}(0.0037)$ \\
\hline$N$ & 184 & 184 & 56 & 56 \\
\hline $\mathrm{R}^{2}$ & 0.0086 & 0.0595 & 0.0127 & 0.0334 \\
\hline
\end{tabular}




\section{Econometric Analysis Results}

The peer effect of adolescent developmental maturity: From Table $\mathbf{2}$ in the natural experiment, it is not difficult to find that in controlling the family characteristics and adopting the fixed school effect method, from the perspective of the individual student, the student's developmental maturity and academic performance are related, that is, Table 2 estimates the results, but this result is undoubtedly endogenous.

In order to further explore the causal relationship between student development maturity and student performance, we give the estimated results of formulas (3) and (4), which are the first and second columns of Table 3. We can find that the development maturity of the students in the class is positively related to the students' performance, but the R2 in both models is smaller. At the same time, through further analysis of the data, we found that in the samples used in column 1 and column 2 of Table 3, the number of boys accounted for $51.65 \%$ and $83.35 \%$, respectively, and the number of boys had certain advantages. In addition, from Table 1, we can find that the ratio of girls entering adolescence increased by $39.69 \%$ within two years, and the proportion of boys entering adolescence increased by $75.54 \%$. In summary, we believe that the results given in Table 3 more reflect the impact of male students' developmental maturity on student performance, and do not fully characterize the impact of developmental maturity of all students, especially female students, on student performance. Existing physiology and psychological studies show that there is a gender difference in the impact of adolescent developmental maturity on males and females, that is, early maturity of boys and late maturity of girls are more favorable for individual development. Therefore, in this study, $\mathrm{P}_{\text {cjg }}^{\text {mat }}$ in equation (1) was replaced by female development maturity $\mathrm{P}_{\text {cjg }}^{\mathrm{gm}}$ and male development maturity $\mathrm{P}_{\text {cjg }}^{\mathrm{bm}}$, respectively. Equations (2) and (4) were treated the same, and new equations (3) and Equation (4). The estimation results are shown in Table 4.

After considering the gender differences in student development maturity, we found that the impact of development maturity on student performance became robust and the corresponding R2 became relatively reasonable. From the first column of Table 4, the maturity of the girls in the class is negatively correlated with the class average and is very significant. When we focus on the peer effect to students who have not yet reached puberty in the class, that is, as shown in column 3 of Table 4, students are still negatively affected by the maturity of the development of girls from the class, which is very significant. The research conclusions are basically the same. The study by Dubas et al (1991) found that the later the girls mature, the higher their academic performance ranks. From the second column of Table 4, the development maturity of the boys in the class has a very significant positive correlation with the average grade of the class. When we only focus on the impact of boys 'developmental maturity on students who have not yet reached puberty in the class, the conclusion is still valid, as shown in column 4 of Table 4, that is, boys' developmental maturity has a positive predictive effect on student performance. The results of Dubas et al (1991) and Daniel et al (1982) are consistent. Both studies show that the sooner a boy matures, the higher his academic performance. The above results also confirm our results in Table 3, that is, the results in 
Table 3 mainly reflect the impact of male students' developmental maturity on student performance.

\section{Robustness Test}

The maturity of puberty is a natural life phenomenon, but if there are factors related to both puberty development maturity ${ }^{4}$ and academic performance, such as: Family economic and social status, learning pressure, then equation (3) the estimation results of equation (4) may be inconsistent. Therefore, this study analyzes the above factors one by one by sample. We divide the students' socioeconomic status and the learning pressure of the three major subjects into high and low according to the median, and perform regression based on formula (4). The results are shown in Tables 5 and $\mathbf{6}$.

From the second line of Table 5, the negative impact of the student's performance on the maturity of the girls in the class still exists in the subgroups with high socioeconomic status, low socioeconomic status, high math pressure, and low math pressure. This is basically consistent with the conclusions in columns 1 and 3 of Table 4, which shows that the conclusions of this article are relatively robust. From the fourth row of Table 5, the development maturity of the boys in the class is positively correlated with the academic performance in different groups. This is basically consistent with the conclusions in columns 2 and 4 of Table 4, which shows that the influence of family socioeconomic status and mathematical pressure on adolescent development and maturity is not serious, and it can basically guarantee that adolescent development and maturity exists independently as exogenous factors.

From the second row of Table 6, it is not difficult to find that the development maturity of class girls has always had a negative impact on student performance, which is consistent with the conclusions in columns 1 and 3 of Table 4. The development maturity of female students has a negative effect on student performance prediction. Looking at the fourth row of Table 6, the impact of the developmental maturity of the boys in the class on the student's performance is positive, indicating that the developmental maturity of adolescence is not seriously affected by the learning pressure of Chinese and English, and the regression results and benchmark regression results (Table 4 columns 2 and 4) are closer. It can be seen that the basic conclusion of this study is relatively stable, that is, the learning pressure does not significantly affect the maturity of adolescence, so the latter can exist as an independent natural factor.

\section{Peer Effect of Developmental Maturity under Different Conditional Quantiles: Heterogeneity Model}

Figure 1 shows the impact of girls' maturity on the performance of non-pubertal students in different quantiles. The horizontal axis represents the conditional quantiles of class girls' developmental maturity, and the vertical axis represents the effects of girls' developmental maturity on performance under different conditional quantiles. In overall, the peer effect of girls' developmental maturity is heterogeneous. Student performance decreases with the increase of conditional quantiles, and has been shown to have a sig- 


\section{Table 5. Peer Effects from Puberty Maturity by Sex: Robustness.}

\begin{tabular}{|c|c|c|c|c|}
\hline & High SES & Low SES & $\begin{array}{l}\text { High Pressure } \\
\text { From Math }\end{array}$ & $\begin{array}{l}\text { High Pressure } \\
\text { From Chinese }\end{array}$ \\
\hline $\begin{array}{l}\text { Puberty Maturity from } \\
\text { Female Students }\end{array}$ & $\begin{array}{l}-0.0069 \\
(0.0047)\end{array}$ & $\begin{array}{l}-0.0385^{\star \star \star} \\
(0.0084)\end{array}$ & $-0.0112^{*}(0.0060)$ & $-0.0203^{* * *}(0.0064)$ \\
\hline $\begin{array}{l}\text { Puberty Maturity from } \\
\text { Male Students }\end{array}$ & $\begin{array}{l}0.0467^{\star \star \star} \\
(0.0067)\end{array}$ & $\begin{array}{l}0.0075 \\
(0.0087)\end{array}$ & $0.0565^{\star * *}(0.0101)$ & $0.0210^{* * *}(0.0061)$ \\
\hline
\end{tabular}

\section{Table 6. Peer Effects from Puberty Maturity by Sex: Robustness.}

\begin{tabular}{|c|c|c|c|c|}
\hline & $\begin{array}{l}\text { High Pressure } \\
\text { from Chinese }\end{array}$ & $\begin{array}{l}\text { Low Pressure } \\
\text { from Chinese }\end{array}$ & $\begin{array}{l}\text { High Pressure } \\
\text { from English }\end{array}$ & $\begin{array}{l}\text { High Pressure } \\
\text { from English }\end{array}$ \\
\hline $\begin{array}{l}\text { Puberty Maturity } \\
\text { from Female Stu- } \\
\text { dents }\end{array}$ & $-0.0185(0.0115)$ & $\begin{array}{l}-0.0148^{* * *} \\
(0.0044)\end{array}$ & $\begin{array}{l}-0.0300^{\star * *} \\
(0.0047)\end{array}$ & $-0.0069(0.0057)$ \\
\hline $\begin{array}{l}\text { Puberty Maturity } \\
\text { from Male Stu- } \\
\text { dents }\end{array}$ & $0.0080(0.0100)$ & $\begin{array}{l}0.0491^{\star \star \star} \\
(0.0058)\end{array}$ & $\begin{array}{l}0.0450^{\star \star \star} \\
(0.0063)\end{array}$ & $0.0187^{\star}(0.0096)$ \\
\hline \multicolumn{5}{|c|}{$\begin{array}{l}\text { Note: } 1 \text {. Robust standard errors is reported in parentheses } \\
2 . \text { All results are estimated by equation (4) and each cell represents a separate regression. } \\
3^{*}: p<0.1,{ }^{\star * *}: p<0.01 \text {. } \\
t: \text { In this subgroup, puberty maturity on score is not significant which result from that the number of size } \\
\text { is small. }\end{array}$} \\
\hline
\end{tabular}

nificant negative impact on most of the quantiles. Before the 70th quantile, the impact of class maturity on student achievement was similar to the regression results of OLS; after the 70th quantile, the negative impact of class maturity on student achievement was affected by the quantile. The increase of the point increases rapidly, and it is obviously larger than the regression result of OLS. The influence reaches the maximum value at the 90th quantile.

Figure 2 shows the influence of boys' developmental maturity on the average performance of non-pubertal students in different quantiles. The horizontal axis represents the conditional quantiles of class boys 'developmental maturity, and the vertical axis represents the impact of boys' developmental maturity on performance in different conditional quantiles. Overall, the peer effect of boys' developmental maturity is heterogeneous. Student performance improves with the increase of conditional quantiles, and the effect on almost all quantiles is always significantly positive. For the 10th to 30th quantiles, student performance decreases as the conditional quantile increases, and for 


\section{Figure1. Peer Effects in Different Quantiles in Male.}

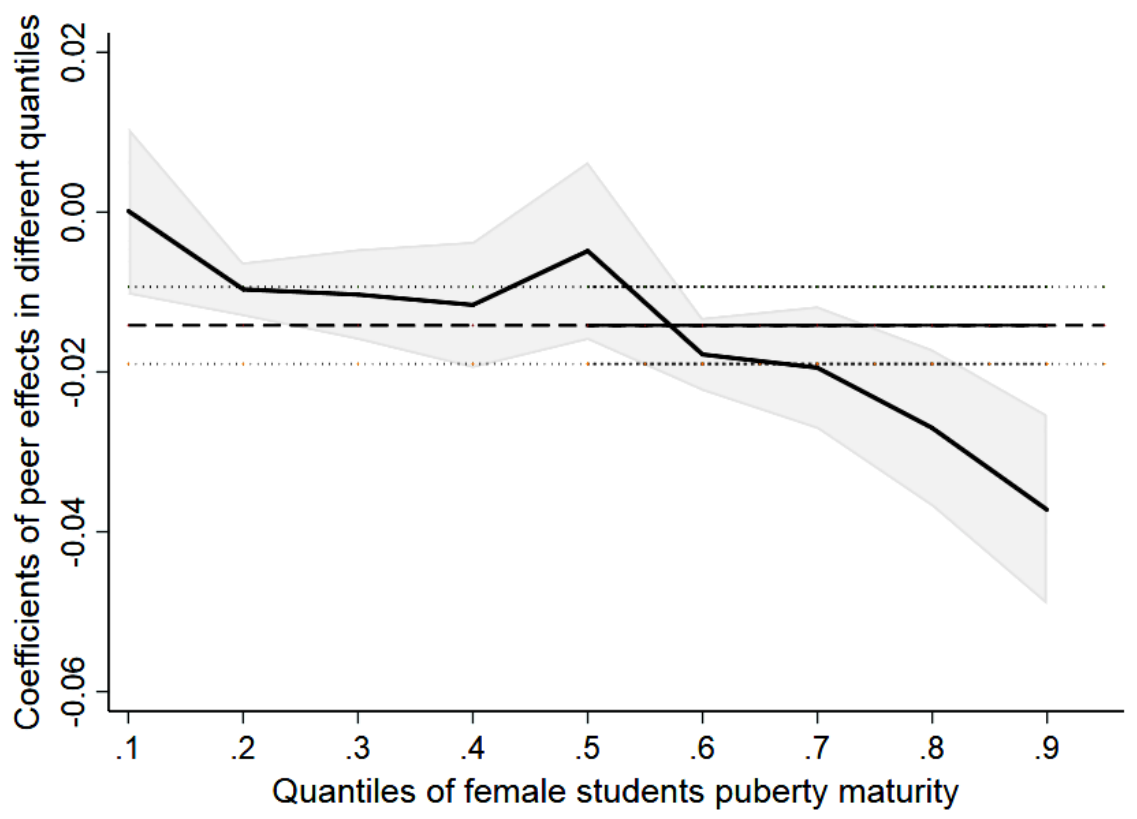

\section{Figure 2. Peer Effects in Different Quantiles in Female.}

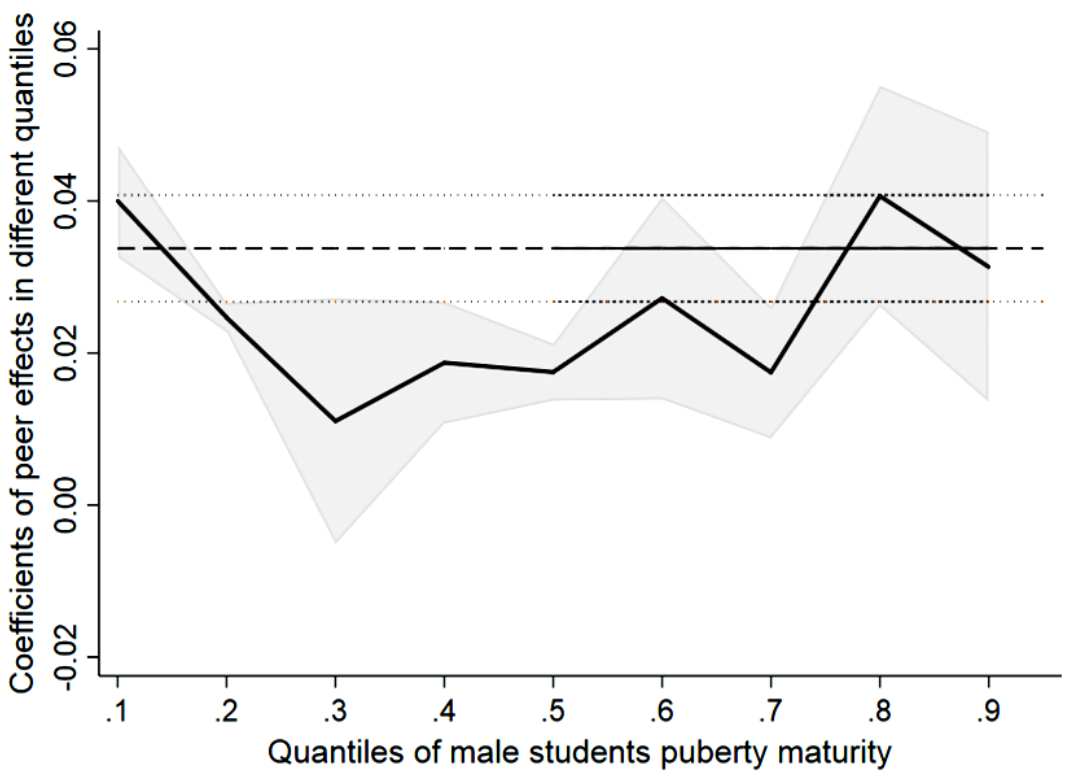


the 30th to 80th quantiles, student performance increases as the conditional quantile increases. After the 80th quantile, the student's performance decreases again with the increase of the conditional quantile, and the effect reaches the maximum at the 90th quantile.

\section{Conclusion and Discussion}

Peer effect, as a classic problem in economics, pedagogy, psychology, and sociology, is of great significance to school placement, school enrollment, and parents' choice of school. However, there are not many domestic studies on the peer effect in mainland China; especially the related studies that have effectively solved the endogenous nature are still scarce. We used the national survey data of CEPS to design natural experiments using changes in the development and maturity of middle school students, and empirically test the peer effect of middle school students in mainland China. This is one of the earlier studies in mainland China to analyze the peer effects of middle school students. This study found that peer maturity has an impact on the academic performance of middle school students, and that this effect has a gender difference. The developmental maturity of boys has a very significant positive correlation with the average class performance, while the developmental maturity of girls has a very significant negative correlation with the average class performance.

This study has certain policy implications for adjusting the school age of school-age children. We found that the peer effect of middle school students 'developmental maturity has gender differences, which confirms and expands the common sense that boys' mental maturity is later than that of girls. Therefore, from the perspective of adolescent development and maturity, the age at which boys and girls enter school should be different. The enrollment age of boys should be slightly behind that of girls of the same age, in order to give full play to the positive impact of higher development maturity and lower maturity of girls on classmates.

This article basically solves the endogenous problem of peer effect estimation, and has played a positive role in enriching related research. However, the following limitations exist: (1) This study analyzes the peer effect of middle school students from the perspective of adolescent development and maturity, but this is only one type of peer effect, and the overall analysis of all types of peer effects has not been achieved. The peer effect has various types and strong endogenous characteristics. It is very difficult to measure all kinds of peer effects completely. Therefore, in order to accurately measure peer effects, existing research can often only identify some types of peer effects. Of course, these studies are undoubtedly helpful for the subsequent overall analysis of all types of peer effects, which is the direction of future efforts. (2) In theory, the most ideal peer effect should be based on the analysis of friends, for example: analysis based on social networks, but this type of research often requires higher quality data, data acquisition is relatively difficult, and everyone's friends change often. It should be said that this type of peer effect is very effective, but it is also not easy to achieve, which is undoubtedly a point for future research. 


\section{Notes}

1. Refers to samples of boys who have entered their age at menarche and girls who have entered their age for the first time, and boys who have not responded to the age of their first sperm and girls who have not responded to the age of their menarche, as well as samples of menarche and the time when their first sperm is younger than 9 years old.

2. When considering only the results of adolescent students (e.g., columns 3 and 4 of Table 4), the valid sample is 2,589 students from 56 classes in 30 schools.

3. Female: $(18.288-13.092) / 13.092=0.3969 ;$ Male $:(7.903-4.502) / 4.502=0.7554 ;$ all students: $(26.191-17.447) / 17.447=0.5012$.

4. Studies have shown that girls 'menarche sooner or later, and boys' first sperm emission sooner or later are affected by factors such as genetics, nutritional status, economic income level, and pressure, and the impact of these factors on the maturity of men and girls can be attributed to differences in family economic and social status The resulting nutritional differences.

\section{References}

Angrist, J. D., \& Lang, K. (2004). Does school integration generate peer effects? Evidence from Boston's Metco Program. Am Econ Rev, 94(5):1613-1634.

Beltz, A. M., \& Berenbaum, S. A. (2013). Cognitive effects of variations in pubertal timing: is puberty a period of brain organization for human sex-typed cognition? Hormon Behav, 63(5):823-828.

Caldas, S. J., \& Bankston, C. (1997). Effect of school population socioeconomic status on individual academic achievement. J Edu Res, 90(5):269-277.

Carman, K. G., \& Zhang, L. (2012). Classroom peer effects and academic achievement: Evidence from a Chinese middle school. Chin Econ Rev, 23(2):223-237.

Cavanagh, S. E., Riegle-Crumb, C., \& Crosnoe, R. (2007). Puberty and the education of girls. Soc Psychol Quart, 70(2):186-198.

Cheng,C. (2017). Peer social capital and academic achievement: Evidence from a ran- domly assigned natural experiment. Sociol Stud, 32(6): 141-164.

Coleman, J. S. (1968). Equality of educational opportunity. Integ Edu, 6(5):19-28.

Daniel Jr, W. A., Duke, P. M., Carlsmith, J. M., Jennings, D., Martin, J. A., Dornbusch, S. M., ... \& Siegel-Gorelick, B. (1982). Educational correlates of early and late sexual maturation in adolescence. J Pediat, 100(4):633-637.

Ding, W., \& Lehrer, S. F. (2007). Do peers affect student achievement in China's secondary schools? Rev Econ Stat, 89(2):300-312.

Dubas, J. S., Graber, J. A., \& Petersen, A. C. (1991). The effects of pubertal development on achievement during adolescence. Am J Edu, 99(4):444-460.

Dunning, T. (2012). Natural experiments in the social sciences: a design-based approach. Cambridge University Press.

Du,.Y.H. \& Yuan,.Y.Z. (2016).The review of the research on peer effect in educa- 
tion:concpt,model and method. Chin Econ Edu Rev, 1(3):34-67.

Freedman,D., Robert, P., and Roger, P. (2007). Statistics. 4th ed. New York:Norton, Inc.

Hanushek, E. A., Kain, J. F., Markman, J. M., \& Rivkin, S. G. (2003). Does peer ability affect student achievement? J Appl Econ, 18(5):527-544.

Hoxby, C. (2000). Peer effects in the classroom: Learning from gender and race variation (No. w7867). National Bureau of Economic Research.

Hoxby, C. M., \& Weingarth, G. (2005). Taking race out of the equation: School reassignment and the structure of peer effects (No. 7867). Working paper.

Ilmarinen, V. J., Vainikainen, M. P., Verkasalo, M. J., \& Lönnqvist, J. E. (2017).

Homophilous friendship assortment based on personality traits and cognitive ability in middle childhood: The moderating effect of peer network size. Eur J Person, 31(3):208219.

Koenker, R., \& Bassett Jr, G. (1978). Regression quantiles. Economet J Economet Soc, 33-50.

Koerselman, K., \& Pekkarinen, T. (2017). The timing of puberty and gender differences in educational achievement.

Lavy, V., \& Sand, E. (2018). The Effect of Social Networks on Students' Academic and Non-cognitive Behavioural Outcomes: Evidence from Conditional Random Assignment of Friends in School. Econ J, 129(617):439-480.
Link, C. R., \& Mulligan, J. G. (1991). Classmates' effects on black student achievement in public school classrooms. Econ Edu Rev, 10(4):297-310.

Lu,. M., \& Zhang,. S. (2007). Non-Market Interaction and Sorting: A Literature Review [J]. China Economic Quarterly, 6(3):9911020.

Manski, C. F. (1993). Identification of endogenous social effects: The reflection problem. Rev Econ Stud, 60(3):531-542.

Manski, C. F. (1999). Identification problems in the social sciences. Harvard University Press.

McKechnie, J. L. (Ed.). (1979). Websters new universal unabridged dictionary. Simon and Schuster.

Moffitt, R. A. (2001). Policy interventions, lowlevel equilibria, and social interactions. Soc Dyn, 4(45-82):6-17.

Sacerdote, B. (2001). Peer effects with random assignment: Results for Dartmouth roommates. Quarterly J Econ, 116(2):681-704.

Sacerdote, B. (2011). Peer effects in education: How might they work, how big are they and how much do we know thus far? In Handbook of the Economics of Education (Vol. 3, pp. 249-277). Elsevier.

Vigdor, J., \& Nechyba, T. (2007). Peer effects in North Carolina public schools. Schools and the equal opportunity problem, 73-101.

Zimmerman, D. J. (2003). Peer effects in academic outcomes: Evidence from a natural experiment. Rev Econ Stat, 85(1):9-23.

Received: 13 November 2019

Revised: 04 December 2019

Accepted: 17 December 2019

The Chinese version of this article has been published in Education and Economy, 2019; 03:40-48. The English version has been authorized for being publication in BECE by the author(s) and the Chinese journal.

杜育红, 郭艳斌. 初中生的同伴效应: 基于发育成熟度的自然实验. 教育与经济, 2019; 03:40-48. 